\title{
Generación blockchain: movimientos juveniles en la era de la web semántica
}

\author{
Carles Feixa, Ph.D. ${ }^{a}$ \\ Profesor Universitat Pompeu Fabra, \\ Cataluña, España
}

carles.feixa@upf.edu

\section{Resumen (analítico)}

Este artículo propone el concepto de Generación B (o blockchain) como paradigma para analizar los movimientos juveniles en la era de la web semántica. Partiendo de conceptualizaciones anteriores sobre la Generación @ (o arroba) y sobre la Generación \# (o hashtag), se presentan el significante, el significado y los rasgos de la Generación B, que se ilustran con el análisis de las protestas de 2019, en el contexto del ciclo de movilizaciones de la última década. El concepto de blockchain o cadena de bloques sirve para reflexionar sobre el tipo de movimientos juveniles surgidos a la salida de la crisis de 2008, que se encadenan en bloques como táctica de resistencia frente a los poderes estatales y corporativos y como forma colaborativa de producir valor frente a la anomia social imperante.

\section{Palabras clave}

Juventud, generación, sociedad de la información, movimientos juveniles, medios sociales.

\section{Palabras clave autor}

Generación @, generación arroba, generación \#, generación hashtag, generación B, generación blockchain.

\section{Thesauro}

Tesauro de Ciencias Sociales de la Unesco.

\section{Para citar este artículo}

Feixa, C. (2021). Generación blockchain: movimientos juveniles en la era de la web semántica. Revista Latinoamericana de Ciencias Sociales, Niñez y Juventud, 19(1), 1-20.

https://dx.doi.org/10.11600/rlcsnj.19.1.4584

\section{Historial}

Recibido: 14.09 .2020

Aceptado: 22.10 .2020

Publicado: 18.12 .2020

Información artículo

Este artículo es el resultado de: el proyecto Transgang (2018-2022). Transnational Gangs as Agents of Mediation. Programa de Investigación e Innovación de la Unión Europea Horizon 2020, European Research Council [grant agreement $n^{\circ} 742705$ ]. Proyecto Genind (2013-2016). La generación indignada: espacio, podery cultura en los movimientos juveniles de 2011: una perspectiva transnacional. Ministerio de Economía y Competividad [CSO2012-34415]. Proyecto Actifem (2019). Activismes en femení. El discurs feminista de dones joves en grups reivindicatius (no feministes) $i$ en la seva quotidianitat. Agaur [2018-Ajove-00003]. Proyecto Yougeca (2019-20). Youth Global Engagement for Climate Action. Acciones de investigación en el marco de la iniciativa de Bienestar Planetario. Universitat Pompeu Fabra [PlanetaryWellbeing-2019]. Área: ciencias sociales. Subárea: interdisciplinaria, antropología. 


\section{Generation Blockchain: Youth in the age of the semantic web}

\section{Abstract (analytical)}

This article proposes the concept of Generation B or Blockchain to analyze youth movements in the era of semantic web. Starting from previous conceptualizations about Generation @ or At sign and about Generation \# or Hashtag, the signifier, meaning and traits of the Generation B are presented, which are illustrated with the analysis of the 2019 protests, in the context of the mobilizations of the last decade. The concept of Blockchain or chain of blocks serves to reflect on the type of youth movements that emerged after the 2008 crisis, that are chained in blocks as a tactic of resistance against state and corporate powers and as a collaborative way of producing value in the face of the prevailing social anomie.

Keywords

Youth, generations, information society, youth movements, social media.

Author Keywords

Generation @, generation at sign, generation \#, generation hashtag, generación B, generation blockchain.

\section{Geração Blockchain: A juventude na era da web semántica}

Resumo (analítico)

Este artigo propõe o conceito de Geração B ou Blockchain para analisar os movimentos juvenis na era da web semântica. A partir de conceituações anteriores sobre Geração @ ou Arroba e sobre Geração \# ou Hashtag, são apresentados o significante, significado e traços da Geração B, que são ilustrados com a análise dos protestos de 2019, no contesto das mobilizações da última década. O conceito de Blockchain ou cadeia de blocos serve para refletir sobre o tipo de movimentos juvenis surgidos após a crise de 2008, que se acorrentam em blocos como tática de resistência contra poderes estatais e corporativos e como forma colaborativa de produção de valor em face da anomia social prevalecente.

Palavras-chave

Juventude, geração, sociedade da informação, movimentos juvenis, meios sociais.

Palavras-chave autor

Geração @, geração arroba, geração \#, geração hashtag, geração B̈, geração blockchain.

Información autor

Catedrático de Antropología Social en la Universitat Pompeu Fabra (Cataluña-España). (iD) 0000-0002-4874-1604. Índice H5: 46. Correo electrónico: carles.feixa@upf.edu 


\section{Prólogo: 1968/2018}

$\mathrm{C}_{\text {de una explosión de movimientos estudiantiles y juveniles que señalarían la par- }}$ tida de nacimiento de los denominados «nuevos movimientos sociales» (NMS). Medio siglo más tarde, nos encontramos ante una nueva oleada de movimientos de protesta, cuyo precedente más inmediato se produce en 2011 (el año de la primavera árabe, de los Indignados en España, del Occupy Wall Street en los Estados Unidos y de varias sacudidas en América Latina, de la Mane colombiana al movimiento estudiantil chileno) y cuya réplica más importante se produce en 2019 (con protestas simultáneas en distintos lugares del planeta, que analizaremos después).

En 2018, además de las conmemoraciones de los sucesos del 68, tuvieron lugar dos jornadas mundiales que actualizaban dos de los «ismos» centrales de los NMS: feminismo y ecologismo. El 8 de marzo de 2018, Día Internacional de la Mujer Trabajadora, tuvo lugar una jornada de lucha bajo lemas como \#MeToo y \#NiUnaMenos, que tuvo la particularidad de un protagonismo especialmente intenso de mujeres jóvenes, especialmente adolescentes, que visibilizaron una nueva sensibilidad de género y nuevas formas de manifestarse. El zo de agosto del mismo año, una adolescente diagnosticada con el síndrome de Asperger, Greta Thunberg, se plantó ante el Parlamento sueco, iniciando la huelga de estudiantes por el clima, que daría nacimiento al movimiento \#FridaysForFuture, que pronto se extendió a otros lugares del mundo y despertó un gran eco mediático. Ambos movimientos - el neofeminista y el neoecologista - eran reacciones frente a problemas socioambientales muy concretos -feminicidio y emergencia climática-, se traducían en un cambio de discurso general —equidad de género, decrecimiento-, se desplegaban en forma de ciberactivismo y tenían como actores de primera fila a adolescentes nacidos en el nuevo siglo - los llamados Millenials-.

Se trata de la base social y tecnológica de lo que propongo denominar Generación blockchain. El concepto de blockchain (o cadena de bloques) nos servirá para reflexionar 
sobre el tipo de movimientos sociales surgidos a la salida de la crisis financiera de 2008 , que aspiran a transformar el valor de cambio en valor de uso y se encadenan en bloques como táctica de resistencia frente a los poderes corporativos y como forma colaborativa de producir valor frente a la anomia social imperante.

\section{Introducción: de la \#Generación a la Generación B}

Este artículo parte de tres textos teóricos sobre las generaciones juveniles en la era contemporánea, publicados en esta misma revista y en otra revista colombiana a lo largo de los últimos veinte años. El primer artículo fue publicado en el año zooo en la revista Nómadas, bajo el título «Generación @: la juventud en la era digital»(Feixa, 200o): consistía en una reflexión teórica sobre el impacto de la primera fase de internet en los mundos de vida juveniles; tal término, y la conceptualización asociada al mismo, se difundió identificándose con los rasgos centrales de la generación juvenil del cambio de siglo (que con posterioridad fue bautizada desde el ámbito anglosajón con el nombre de Millennial). El segundo artículo fue publicado en 2006 en la Revista Latinoamericana de Ciencias Sociales, Niñez y Juventud, bajo el título «Generación XX: teorías sobre la juventud en la era contemporánea» (Feixa, 2006): consistía en un balance de las principales conceptualizaciones sobre la juventud en el pensamiento social a lo largo del siglo XX. El tercer artículo fue escrito en colaboración y publicado en esta misma revista en 2016, bajo el título «Generación hashtag: la juventud en la era de la web social»; consistía en una reflexión teórica sobre la segunda generación digital (o era hiperdigital) y su impacto en los movimientos juveniles de 2011 (Feixa et al., 2016). ${ }^{1}$ Dos décadas después de mi primera incursión al tema, cuando la Generación @ llega a su mayoría de edad, me propongo reflexionar sobre la metamorfosis de la juventud en lo que propongo denominar era de la web semántica o era transdigital, a partir de un nuevo concepto: el de Generación B o blockchain. Como hice con los conceptos anteriores, empezaré describiendo el significante, seguiré exponiendo el significado que le atribuyo y finalizaré analizando los principales rasgos de la Generación B, que comparo con los de la Generación @ o arroba y con los de la Generación \# o hashtag. ${ }^{2}$

\footnotetext{
${ }^{1}$ Ese mismo año resumí tales conceptos, así como algunos estudios empíricos en los que se basaban, en el libro DelaGeneración@a la \#Generación (Feixa, 2016).

${ }^{2}$ Los tres artículos se cuentan entre mis publicaciones más citadas. Según Google Scholar, a fecha de 15 de agosto de 2020, el primer artículo ha recibido 179 citas; el segundo 345 y el tercero y más reciente 67.
} 


\section{Método}

El presente texto es de naturaleza teórica, aunque se basa en varios proyectos de investigación en los que he participado durante la última década. En los dos primeros he sido investigador principal: el proyecto GENIND (2013-2016) se planteó como objetivo analizar los movimientos juveniles surgidos en 2011 en tres regiones donde se vivieron con particular intensidad —el sur de Europa, el norte de África y América Latina-, desde una perspectiva comparativa (Feixa \& Nofre, 2013; Feixa et al., 2016; Sánchez-García et al., 2019); el proyecto Transgang (2018-2022) tiene por objeto estudiar los grupos juveniles de calle como agentes de mediación, en las mismas regiones, desarrollando para ello una metodología transnacional (Feixa et al., 2019; Feixa \& Andrade, 2020). En los otros dos proyectos he sido asesor, participando en la discusión de los resultados: el proyecto ACTIFEM (2018-2019) se centró en las nuevas formas de activismo juvenil femenino en la vida cotidiana, en grupos feministas y no feministas, surgidos a raíz de las masivas movilizaciones del 9 de marzo en los últimos años (Pires \& Feixa, en prensa); el proyecto YOUGECA (2019-2020) es una investigación en curso sobre el activismo juvenil por el clima y el movimiento Fridays for Future (Feixa, 2020). En todos estos proyectos se ha utilizado una metodología cualitativa, que incluye observación participante, entrevistas en profundidad e historias de vida, comparando los datos recogidos a nivel local a través del extended-case method (Burawoy, 1998).

Las preguntas de investigación que han orientado dichas investigaciones pueden resumirse en tres: a) ¿cuáles son las semejanzas y diferencias de los movimientos juveniles surgidos en las tres regiones señaladas (sur de Europa, norte de África y América Latina) durante la última década?; b) ¿cuál es el rol de la juventud en dichos movimientos, movidas y movilizaciones, ya sea como agente impulsor, participante o simpatizante?; c) ¿qué impacto tienen las tecnologías digitales en la gestación, difusión y derivas de tales movimientos?

Aunque en el presente texto no utilizamos directamente los datos empíricos obtenidos de dichos estudios, partimos de sus conclusiones analíticas para construir nuestro paradigma teórico y para encuadrar nuestro análisis histórico y geográfico. Dichas conclusiones analíticas pueden resumirse en tres grandes líneas: a) las movilizaciones tienen un fuerte componente glocal pues, aunque responden a circunstancias geopolíticas y regímenes de poder locales, se hacen visibles en un marco global que las interconecta y las hace comparables; b) la juventud tiene un rol preponderante en todos los movimientos como principal agente impulsor de los mismos, aunque por ello atrae sobre sí el estigma 
de su tratamiento mediático y en casos extremos la persecución juvenicida; c) las tecnologías digitales no explican el origen de las protestas, pero ayudan a entender su rápida difusión y las formas de organización descentralizadas y reticulares que las caracterizan, que al mismo tiempo reflejan una doble brecha digital, generacional y de clase.

\section{Generación B: el significante}

En abril de 2018 la Cátedra de Estética del Institut Valencià d'Art Modern (IVAM) me invitó a impartir un seminario y una conferencia titulada De la tribu a la red. En la misma desarrollé las ideas sobre la Generación@ y la \#Generación (es decir, sobre el paso de Internet 1.o a Internet 2.0 y cómo esta transformación afectó a los jóvenes), las cuales había sintetizado en mi libro De la Generación@ a la \#Generación (Feixa, 2016). Al terminar la charla con la sala llena, se me acercaron dos mujeres jóvenes que se habían quedado sin poder preguntar. Se mostraron entusiasmadas con el contenido de la charla, pero me comentaron que debía incluir Internet 3.0 y el concepto de blockchain (cadena de bloques). Aunque había oído hablar del primer término (menos del segundo), no tenía claro su significado, por lo que les pedí referencias: no me recomendaron ningún libro, sino un tutorial de Youtube sobre el tema (una clase TED). Al cabo de unos días lo busqué en internet y encontré multitud de referencias, incluyendo definiciones de la Wikipedia y varios videos en Youtube. Según estas referencias, la denominación Web 3.o surgió en 2006, aunque no se difundió hasta unos años después, para referirse a la llamada «web semántica», una confusa amalgama de fenómenos que incluyen la transformación de la red en big data, la inteligencia artificial, el internet de las cosas, la web 32 D, la personalización de internet, etc. ${ }^{3}$ Según la definición de la Wikipedia:

Web 3.o es la web que facilita la accesibilidad de las personas a la información, sin depender de qué dispositivo use para el acceso a ella, una web con la que interactuar para conseguir resultados más allá del hecho de compartir «información» (sic.), que esta información sea compartida por cada persona de una forma inteligible y de provecho para ella y sus necesidades en cada circunstancia, y que, además, está diseñada bajo parámetros de rendimiento eficiente, optimizando los tiempos de respuesta, optimizando los consumos energéticos

\footnotetext{
${ }^{3}$ En este artículo he optado por priorizar la webgrafía frente la bibliografía, incluyendo referencias a la Wikipedia, por su mayor atención a fenómenos emergentes, y porque su valor académico no depende de dónde se publique sino de su valor informativo: las fake news pueden encontrarse en todos los sitios. Ver «Web 1.o, 2.0, 3.0» (2019) y «Cadena de Bloques» (2019).
} 
globales del sistema, optimizando las exigencias técnicas y tecnológicas, optimizando los conocimientos y capacidades que se requiera al usuario ya que es una web más intuitiva, humanizada... Una web enfocada al bien común, a la integración universal de las personas y ser herramienta para el desarrollo sostenible. («Web 3.0», 2019)

Lo que llamó mi atención fue un TED de un joven argentino, Nicolás Palacios, titulado Revolución de la Web 3.o (Palacios, 2017), que supuse que es al que se referían las mujeres jóvenes que me interpelaron en el IVAM. Visualizo el vídeo de 14:24 minutos, que se presenta con este enigmático subtítulo: Internet de los valores. Avances que permitirán traspasar valores por internet sin intermediarios. Al leer «valores» supongo que se refiere a valores morales o éticos, tan etéreos como internet, y deduzco que la charla irá de la ética de la red (la «nética»). Craso error: la misma parte de lo contrario, del valor del dinero (de las criptomonedas). El joven conferenciante explica la tecnología blockchain, lo que es y las grandes implicaciones que puede tener en el futuro. Según él, es un protocolo de internet que permite tener un registro «sobre roca» de todas las acciones que han pasado sobre una cadena de datos organizados en bloques (de ahí el término).

La noción cadena de bloques fue utilizada primero por Bitcóin en 2009, que propuso el logo del término: una B que imitaba al dólar (B). La base del concepto es que permite validar la confiabilidad de unos datos en base a su trazabilidad, sin necesidad de una autoridad de certificación superior. Pero los beneficiados no son solo los usuarios de las criptomonedas: la tecnología blockchain permite crear aplicaciones autónomas sin pasar por intermediarios o, como dice Palacios (2017), «que todo tipo de personas creativas puedan generar valor y compartirlo». Según la Wikipedia, «se considera una tecnología en la que la verdad (estado confiable del sistema) es construida, alcanzada y fortalecida por los propios miembros; incluso en un entorno en el que exista una minoría de nodos en la red con comportamiento malicioso» («Cadena de datos», 2019). Eso es precisamente lo que permite que la información deje de ser patrimonio del emisor y pase a ser resultado de un trabajo colaborativo, descentralizado, en línea, llevado a cabo por comunidades virtuales con un fuerte componente juvenil y lúdico.

Con posterioridad descubrí y adquirí (naturalmente por Amazon) el libro referente sobre el tema, titulado La revolución blockchain (Tapscott \& Tapscott, 2016). Significativamente, el primer firmante era Don Tapscott, autor del ensayo en el que me basé para conceptualizar la Generación @: Growing up digital: The rise of the net generation (1998); el segundo autor era su propio hijo, Alex Tapscott. En el primer ensayo el autor pronosticaba la emergencia de una generación que había crecido a fines del siglo XX rodeada de 
bites, que se había educado con videojuegos, que al llegar a la juventud había aprendido a navegar en el ciberespacio y que al transitar a la vida adulta estaba predestinada a revolucionar la economía y la sociedad:

Por primera vez en la historia, los niños saben más que sus padres sobre una innovación central para la sociedad. Es a través del uso de estos medios digitales que la Generación de la Red desarrollará e impondrá su cultura al resto de la sociedad. (Tapscott, 1998, pp. 1-2)

En el nuevo ensayo, los Tapscott exponen con detalle el desarrollo de la tecnología blockchain, cuya creación en 2008 por Satoshi Nakamoto (seudónimo de una persona o grupo de personas) coincidió con el inicio de la crisis financiera internacional. El protocolo del bitcóin se basaba en un sistema de pago electrónico directo y entre iguales (peerto-peer o $\mathrm{P}_{2} \mathrm{P}$ ), el cual garantiza la integralidad de la información intercambiada entre millones de ordenadores sin pasar por terceros, lo que permite extenderlo a los negocios, pero también a los gobiernos y a los activistas sociales:

Más que un internet de la información, es un internet del valor o del dinero. También es una plataforma que permite a todo el mundo saber lo que es la verdad, al menos con respecto a la información que se registre de manera estructurada. (Tapscott \& Tapscott, 2016, p. 104)

El bitcóin no se guarda en archivos que estén en un lugar concreto, sino que son transacciones que se registran en una cadena de bloques distribuidos por todo el mundo, públicos y encriptados:

Algunos estudiosos han afirmado que la invención de la contabilidad por partida doble permitió el nacimiento del capitalismo y de la nación-Estado. Este nuevo registro digital de transacciones económicas puede programarse para asentar prácticamente todo lo que tenga valor e importancia para la humanidad. (Tapscott \& Tapscott, 2016, pp. 106-107)

Como sucedió con el ensayo sobre la net generation, los autores sobrevaloran los aspectos positivos del cambio tecnológico y menosprecian sus efectos perversos o no

\footnotetext{
${ }^{4}$ Cabe decir que cuando redacté el artículo sobre la Generación @ (Feixa, 200o) no conocía el libro de Tapscott. Como se adecuaba a mis planteamientos, lo introduje en mi texto sobre la Generación XX (Feixa, 2006) y lo desarrollé en el de la Generación \# (Feixa, 2016).
} 
deseados.5 Pero dan en la clave en lo esencial: el blockchain es algo mucho más grande que el dinero, pues se basa en una confianza descentralizada y en red que permite crear valor no solo monetario o material sino también inmaterial o moral. Posibilita lo que puede denominarse «menoma»: «la idea de una identidad digital soberana e inalienable, una identidad que ni nos da ni nos quita administración central y que es aplicable en todos los contextos - en persona u online- y en cualquier parte del mundo» (Tapscott \& Tapscott, 2016, p. 53). En el epílogo a la nueva edición del libro, los autores hablan de un «nuevo contrato social para la era digital», que bautizan algo enfáticamente como «Declaración de Interdependencia», basada en derechos de nuevo tipo, como la identidad segura, la educación centrada en el estudiante, la seguridad económica y medioambiental, la paz con dignidad y la responsabilidad política e institucional: «La redes permiten a los ciudadanos participar plenamente en su propio gobierno y ahora podemos iniciar una nueva era democrática basada en una cultura de debate público y ciudadanía activa» (Tapscott \& Tapscott, 2016, p. 521).

\section{Generación B̈: el significado}

Si aplicamos los conceptos de web semántica y blockchain a la generación juvenil actual podemos relacionarlo con el contexto socioeconómico de la salida de la crisis, la búsqueda de nuevos nichos económicos en las redes colaborativas, el trueque o el intercambio de servicios como alternativa a la economía monetaria, la deslocalización de las culturas juveniles y la crisis de la propia noción de juventud. Simplificando mucho: los jóvenes ya no buscan la verdad en una entidad superior, sino en las redes de confianza mutua construidas por ellos y ellas. Entendemos por web semántica el entorno de la web 3.o, centrada en la personalización de internet y en los intercambios de valores materiales y morales que la identidad digital posibilita. Entendemos por era transdigital, no el fin del digitalismo como tecnología o como praxis cotidiana, sino más bien la superación del digitalismo como ideología, con un cierto retorno a espacios no tecnológicos, a las comunidades primarias y a las afinidades electivas. La crisis afectó profundamente a la juventud, traduciéndose en precariedad laboral, migraciones transnacionales (de sur a norte, pero también de norte a norte, de norte a sur y de sur a sur), retraso de la emancipación y refugio en las redes sociales.

\footnotetext{
${ }^{5}$ La coincidencia de la publicación del libro con la elección de Trump y con el Brexit demuestra que la tecnología blockchain no tiene ideología y puede tener usos y abusos por parte de los neocons.
} 
Por generación transdigital entendemos la nacida en el tránsito al nuevo siglo, hiperconectada desde la primera infancia en los albores del nuevo milenio, que llegó a la preadolescencia en plena crisis, vivió a distancia la emergencia de los movimientos indignados y entra en la juventud coincidiendo con el final oficial de la crisis, pero también con el auge de movimientos neoconservadores, xenófobos (y juvenófobos) a escala planetaria. Por otra parte, es la generación que protagoniza la renovación del movimiento feminista, con la implicación de adolescentes y jóvenes en los movimientos \#NiUnaMenos y \#MeToo y en el 8M de 2018 y 2019. Por otra parte, protagoniza la emergencia del movimiento contra el cambio climático (\#FridaysForFuture). La juventud se convierte en la edad de moda, en forma de culto por la imagen, anti-aging, paradigma de la innovación tecnológica y de la experimentación social. Al mismo tiempo, los jóvenes de carne y hueso ven cómo se consolidan los recortes sociales, educativos y laborales establecidos durante la crisis, se les excluye de la toma de decisiones y se generalizan intentos de censura o control de la red con la excusa de combatir las fake news. Para contener el riesgo de morir de éxito, la juventud se encadena en bloques para prevenir un futuro incierto, generando una inteligencia colectiva, como los cyborgs.

\section{Generación B̈: los rasgos}

Aventurándome a ser futurólogo, intentaré deducir de la categorización anterior los rasgos emergentes de la generación transdigital, precisando que se trata de una especulación sin sustento todavía en estudios empíricos. ${ }^{6}$

a) Generación \# versus Generación B: cuando los adultos hemos aterrizado finalmente en las redes sociales, convirtiéndolas en fundamento de la posverdad, los adolescentes y jóvenes escapan de las mismas, buscando otros territorios a colonizar. Primero fue Instagram, una red social que privilegia la imagen y los emoticones. Después empezaron a colaborar en línea con cadenas de metadatos, para liberarse de las ataduras del sistema, pero también para confirmar su condición precaria. Un ejemplo significativo de lo que vengo diciendo es la llamada «Torre de la verdad». Se trata de la creación por Facebook de una unidad encargada de vigilar las fake news, instalada en varias plantas de la Torre Agbar

\footnotetext{
${ }^{6}$ Estos rasgos se han formulado a partir de la juventud europea y su aplicación debe estar atenta a las desigualdades y brechas que internet genera, sin que ello suponga postular la excepcionalidad de otros casos, como el latinoamericano: la mayoría de los jóvenes del planeta están hoy conectados al mundo digital y a las redes sociales, aunque la intensidad, calidad y grado de su conectividad varíen (ver Muñoz, 2010).
} 
de Barcelona (en el distrito 22@ donde tiene la sede mi universidad y varias empresas audiovisuales y tecnológicas). En la misma trabajan centenares de jóvenes hiperformados, pero con sueldos mileuristas.

b) Espacio glocal versus no lugar: la vuelta globalizada a la localidad, visualizada por ejemplo en la comunidad presencial y online que ocupó las plazas del ${ }_{15} \mathrm{M}$, corre el peligro de transformarse en un «no lugar». Uso libremente aquí el concepto acuñado por Marc Augé (1996) para designar la ubicuidad del espacio juvenil, entre su expulsión del espacio público, la supervisión y comercialización de los espacios de ocio, la desorientación del hiperespacio, el anonimato de los nuevos centros comerciales y la vuelta a la habitación. La multiplicación de los espacios se convierte en sensación de no lugar para los jóvenes, perdidos en el no-man's-land (o mejor en el no-women's-land) de una adolescencia y juventud prolongadas o eternas (que algunos denominan emerging adulthood y otros adultescencia). Al mismo tiempo, la tecnología se deslocaliza, como puso de manifiesto la fiebre de Pokemon Go durante 2016.

c) Tiempo viral versus slow time: a la salida de la crisis y tras la resaca de los movimientos sociales post-2011, la juventud experimenta la vuelta a un tiempo más pausado: el slow time. Este se conecta con otros movimientos que elogian la lentitud: slow food, slow travel, slow work, etc. Por una parte, los jóvenes que crecieron en el hiperdigitalismo buscan espacios libres de tecnología. Por otra parte, incorporan plenamente la tecnología en su yo interior, sin el dualismo persona-máquina de generaciones anteriores (que remite al dualismo judeocristiano original cuerpo-espíritu). Adolescentes y jóvenes no tienen problemas en combinar espacios-tiempos de hiperconexión con espacios-tiempos de desconexión, cronotopos hiperdigitales y cronotopos analógicos. La lentitud como entrenamiento de la velocidad.

d) Translocalismo versus The Wall: la crisis de los refugiados del próximo oriente y del África subsahariana, la caravana de migrantes centroamericanos y el auge de la extrema derecha a escala global convierten el translocalismo en construcción de nuevas fronteras, físicas o simbólicas, normalmente erigidas por adultos (nativos territoriales y migrantes digitales) para impedir el paso de jóvenes (migrantes territoriales y nativos digitales). Un caso emblemático son los tres referendos que tuvieron lugar en 2016: las presidenciales en los Estados Unidos, el Brexit y el acuerdo de paz en Colombia. En los tres casos ganaron opciones contrarias al translocalismo, que buscaban erigir fronteras o retornar a un pasado sin mezclas, opciones apoyadas por los mayores, mientras que los jóvenes votaron en un sentido radicalmente contrario (contra Trump, contra el Brexit, por la paz): las 
viejas generaciones imponían así un futuro con fronteras a las nuevas generaciones que querían vivir sin ellas. Como sucede con los caminantes blancos de Juego de tronos, el muro pretende establecer claras delimitaciones étnicas, de género o generación frente al miedo al otro (al diferente). Pero la tecnología blockchain, en este caso, rompe las fronteras y experimenta con no lugares transfronterizos.

e) Rizoma versus Holograma: la revolución rizomática teorizada por Castells (2012) no se ha extinguido, pero corre en riesgo de transformarse en una fantasmagoría: en holograma. En unos tiempos en que la realidad virtual y el $4 \mathrm{D}$ se generalizan, en que se puede imprimir a distancia cualquier prototipo multidimensional, en que un político encarcelado participa en reuniones electorales mediante su holograma, la cultura juvenil parece recrear la Holesección de Star Trek: el espacio de la nave interestelar donde los navegantes se relajaban con juegos de realidad virtual, en forma de hologramas que los transportaban a espacios y tiempos pasados o futuros, reales o imaginarios. Del mismo modo, la mente transdigital de la Generación blockchain transforma las raíces del rizoma en hologramas futuristas, convirtiéndolos en cazadores de tendencias - trendsetters- capaces de prefigurar la sociedad y la tecnología del futuro.

\section{Generación B̈: los movimientos de 2019}

Para mostrar que la Generación blockchain no es una idea abstracta, sino que es una noción que puede servir para analizar los movimientos juveniles contemporáneos, presentaré brevemente el ciclo de protestas que tuvo su epicentro en el año 2019. Este año estuvo marcado por una sucesión de protestas que, pese a replicar de algún modo las surgidas en 2011, se presentaban con nuevos rasgos y aceleraron con particular intensidad la aparición de movidas, movilizaciones y movimientos simultáneos en varios lugares del mundo (Aguilera, 2008), lo que llevó al The Washington Post a declarar al manifestante callejero como el protagonista del año: «la columna vertebral del movimiento fueron los jóvenes, incluyendo a los adolescentes» (Diehl, 2019, ver Pleyers, 2020).

Como sucedió ocho años antes, el nuevo ciclo de protestas se inició en los países árabes (tabla 1): el 19 de febrero en Argelia (uno de los pocos países donde la mecha de la primavera árabe no había prendido) tuvieron lugar masivas manifestaciones juveniles que acabaron con la dimisión del primer ministro que gobernaba el país con manos de hierro desde hacía décadas; el 20 de septiembre en Egipto — cuna de la primavera árabe- tuvie- 
ron lugar protestas duramente reprimidas por el régimen militar; en Túnez —el único país donde había triunfado la primavera árabe- los jóvenes volvieron a protagonizar marchas pro democracia real; y en Marruecos tuvieron lugar protestas duramente reprimidas pidiendo mayor autonomía y libertad (ver Sánchez-García \& Touthou, 2021).

\section{Tabla 1}

Cronología de los movimientos sociales de 2019

\begin{tabular}{|c|c|c|c|c|c|}
\hline \multicolumn{6}{|c|}{ Protesta, manifestación o revolución } \\
\hline Inicio & País/localidad & Evento & $\begin{array}{l}\text { Jefes de Gobierno o } \\
\text { Estado eliminados }\end{array}$ & Continente & Final \\
\hline 17.11.2018 & Francia & $\begin{array}{l}\text { Movimiento de los chalecos } \\
\text { amarillos }\end{array}$ & Ninguno & Europa & En marcha \\
\hline 19.12.2018 & Sudán & Revolución sudanesa & $\begin{array}{l}\text { Omar al-Bashir } \\
\text { (presidente) }\end{array}$ & África & En marcha \\
\hline 4.02 & Kazajistán & Protestas en Kazajistán & $\begin{array}{l}\text { Bakhytzhan Sagintayev } \\
\text { (primer ministro) } \\
\text { Nursultan Nazarbayev } \\
\text { (presidente) }\end{array}$ & Asia & En marcha \\
\hline 16.02 & Argelia & Protestas en Argelia & $\begin{array}{l}\text { Abdelaziz Bouteflika } \\
\text { (presidente) }\end{array}$ & África & En marcha \\
\hline 15.03 & $\begin{array}{l}\text { Hong Kong } \\
\text { (China) }\end{array}$ & Protestas en Hong Kong & $\begin{array}{l}\text { Wang Zhimin } \\
\text { (director Oficina Enlace } \\
\text { Gobierno Popular Central } \\
\text { en Hong Kong) }\end{array}$ & Asia & En marcha \\
\hline 24.03 & Reino Unido & $\begin{array}{l}\text { Salida del Reino Unido de la } \\
\text { Unión Europea }\end{array}$ & Ninguno & Europa & 31.01 .2020 \\
\hline 8.07 & $\begin{array}{c}\text { Puerto Rico } \\
\text { (Estados Unidos) }\end{array}$ & Protestas en Puerto Rico & $\begin{array}{l}\text { Ricardo Rosselló } \\
\text { (gobernador) }\end{array}$ & América & 12.08.2019 \\
\hline 14.07 & Moscú (Rusia) & Protestas en Moscú & Ninguno & Europa & 29.09.2019 \\
\hline 20.09 & Egipto & Protestas en Egipto & Ninguno & África & 27.09.2019 \\
\hline 01.10 & Irak & Protestas en Irak & $\begin{array}{l}\text { Adil Abdul-Mahdi } \\
\text { (primer ministro) }\end{array}$ & Asia & En marcha \\
\hline 02.10 & Ecuador & Protestas en Cataluña & Ninguno & América & 13.10 .2019 \\
\hline 14.10 & $\begin{array}{l}\text { Cataluña } \\
\text { (España) }\end{array}$ & Protestas en Cataluña & Ninguno & Europa & 20.11.2019 \\
\hline 14.10 & Chile & Protestas en Chile & Ninguno & América & En marcha \\
\hline 14.10 & Italia & $\begin{array}{l}\text { Movimiento de las } \\
\text { Sardinas }\end{array}$ & Ninguno & Europa & En marcha \\
\hline 17.10 & Líbano & Protestas en Líbano & $\begin{array}{l}\text { Saad Hariri } \\
\text { (primer ministro) }\end{array}$ & Asia & En marcha \\
\hline 21.10 & Bolivia & Protestas en Bolivia & Evo Morales (presidente) & América & 26.11.2019 \\
\hline 15.10 & Irán & Protestas en Irán de 2019 & Ninguno & Asia & En marcha \\
\hline 20.10 & Malta & Protestas en Malta & $\begin{array}{l}\text { Joseph Muscat } \\
\text { (primer ministro) }\end{array}$ & Europa & En marcha \\
\hline 04.12 & India & Protestas en India & Ninguno & Asia & En marcha \\
\hline
\end{tabular}

Nota. Fuente de datos Wikipedia («Movimientos sociales de 2019», 2020). 
El segundo nicho geográfico de las protestas fue Asia: el 15 de marzo en Hong-Kong, el precario enclave democrático de China, resurgió el Umbrella Movement de 2015, encabezado también por líderes estudiantiles; una protesta pro democracia y libertad de expresión que todavía dura y sobre la que se ha cernido una represión sistemática (Fernández-Planells, 2015); el 15 de noviembre en Irán los jóvenes volvieron a la calle, como lo habían hecho en 2007 (el primer antecedente de las ciberprotestas de 2011) para reclamar una apertura del régimen de los ayatollahs; y el 4 de diciembre, en India, explotaron protestas contra el gobierno fundamentalista hindú.

El tercer foco de las protestas fue el sur de Europa. El 14 de octubre empezaron en Cataluña masivas protestas contra la sentencia que condenaban a líderes políticos y sociales independentistas a duras penas de cárcel por sedición, con un marcado protagonismo juvenil simbolizado en la quema de mobiliario público en los centros urbanos. El movimiento se difundió a través de plataformas en línea sin liderazgos visibles (Soler et al., en prensa). El mismo 14 de octubre nacía en Italia el movimiento de los Sardinas para impedir la llegada al poder del xenófobo Salvini, protagonizado por una nueva generación de jóvenes que rechazaban la mezcla de neofascismo y neopopulismo del líder italiano, quien había hecho bandera su rechazo a los refugiados y a los emigrantes procedentes de África. También en Francia prosiguió el movimiento de los chalecos amarillos contra las políticas neoliberales de Macron, aunque en este caso los protagonistas no eran jóvenes sino otros sectores precarizados.

El cuarto y último foco de la protesta fue América Latina: en otoño se visibilizaron o explotaron conflictos en Chile, Bolivia, Ecuador, Colombia, Nicaragua y Honduras, protagonizados por jóvenes estudiantes, activistas o miembros de organizaciones juveniles de calle, en alianza con movimientos indígenas o campesinos, que se enfrentaron a gobiernos neoliberales o neosocialistas de signo populista. Aunque se oponían a gobiernos de signo opuesto, todos ellos tenían en común el rechazo a la eternización en el poder de algunos de sus dirigentes, al reclamo de una democracia más participativa, el combate de políticas de ajuste económico que afectaban de manera particularmente dramática a jóvenes y minorías, el cansancio por los crecientes casos de corrupción, la persistencia de la desigualdad y la denuncia de la impunidad frente al feminicidio y al juvenicidio (ver los artículos incluidos en este monográfico).

Todos estos movimientos respondían a factores locales o nacionales muy concretos, pero al mismo tiempo buscaban la visibilidad pública y su conexión con otras protestas transnacionales, cuya multiplicación a través de las redes sociales las hicieron virales. 
Aytaç y Stokes (2020) argumentan que la ola de protesta de 2019 fue un «tsunami de manifestaciones masivas de fin de década» en el contexto de la primavera árabe (el movimiento catalán se denominó precisamente \#TsunamiDemocratic). Diehl (2019) señala dos factores comunes a todas las protestas de 2019: las redes sociales en línea y «una generación creciente de jóvenes descontentos que son dueños de ella, los dos han cambiado el equilibrio de poder entre el gobierno y la sociedad en los estados democráticos y autoritarios». A diferencia de las protestas de 2011, mayoritariamente pacíficas, en este caso la ira se extendió y se usó una violencia performativa dirigida hacia las cosas y hacia los agentes del orden. La ocupación de plazas centrales fue remplazada por huelgas, marchas y piquetes más puntuales, pero más airados. La fase más dura de la crisis económica había terminado, pero la situación de precariedad vital en la que se sumía a los jóvenes y a otros sectores vulnerables de la población se hizo más evidente.

\section{Epílogo: 2020}

El 26 de mayo de 2020, en plena pandemia mundial por el coronavirus, el asesinato del joven afroamericano George Floyd a manos de un policía en Minnepolis (Estados Unidos), despertó una oleada de rabia y malestar en contra del racismo y del abuso policial. Las manifestaciones y protestas tuvieron lugar inicialmente de manera pacífica, pero desde el día siguiente comenzaron los actos de violencia. Tras varias actuaciones desproporcionadas por parte de la policía, la protesta se convirtió en revuelta y durante los disturbios se produjeron saqueos, asaltos e incendios provocados que culminaron el incendio de tres estaciones de policía. A partir del 31 de mayo, hubo protestas simultáneas en más de 100 ciudades de Estados Unidos y en otros lugares del mundo («Protestas por la muerte de George Floyd», 2020).

De algún modo, los disturbios por Floyd completan la trilogía de NMS surgidas en torno a 1968: al neofeminismo y al neoecologismo se añade lo que puede denominarse «neocivilismo» (un movimiento pro derechos civiles de las minorías étnicas o raciales que no se resignan a seguir en una posición subalterna y aspiran a ser reconocidos con derechos plenos, a partir de un discurso antirracista y poscolonial). Lo significativo es que 50 años después del 68, el relevo lo tomaba una nueva generación de jóvenes, usando renovadas tecnologías de protesta, articuladas en torno a internet 3.o (por ejemplo, compartir fotos y videos en tiempo real), que desde Minneapolis se difundieron a otras 
ciudades norteamericanas y, de allí, a todo el mundo occidental; y de los afroamericanos pasaron a involucrar a otras minorías racializadas o victimizadas. ${ }^{7}$

En un artículo publicado en 2009, escrito con Inês Pereira y Jeff Juris (uno de los grandes investigadores sobre los movimientos sociales en red, recientemente desaparecido), analizábamos la participación juvenil en tres tipos de movimiento social: los movimientos sociales «clásicos» (desde mediados del siglo XIX a 1968); los «nuevos» movimientos sociales (de 1968 hasta fines de siglo XX); y los «novísimos» movimientos sociales (la primera década del siglo XXI) (Feixa et al., 2009; Juris, 2008). Los primeros se basaban en una ideología adultocéntrica, usaban un repertorio de protesta surgido del movimiento obrero (de la huelga a la marcha) y se comunicaban mediante la galaxia Guttenberg (de la oralidad a la escritura); los segundos se basaban en una ideología juvenocéntrica, usaban un repertorio de protesta performativo (de los sitting-in a los happenings) y se comunicaban mediante la galaxia MacLuhan (de la escritura a los medios); los terceros se basaban en una ideología intergeneracional, inventaban un repertorio digital de protesta (de los flash-mobs al ciberactivismo) y se comunicaban mediante la galaxia Internet (de los medios a lo transmedia). Cabe preguntarse si el ciclo de protestas de la segunda década del siglo XXI forma parte de esta última categoría o responde a otro paradigma. ${ }^{8}$

Si comparamos la Generación B con las Generaciones @ y \# que la precedieron, podemos constatar diferencias en cuanto a su periodización, contexto social, protagonistas, rasgos principales y ejemplos (tabla 2). La Generación @ nace en torno a 1980, 1lega a la juventud coincidiendo con la emergencia de la primera era digital (de internet 1.o), en el contexto del capitalismo informacional en expansión y de la nueva economía. La Generación \# nace en torno a 1990, llega a la juventud coincidiendo con la crisis financiera de 2008, con la expansión de las redes sociales (de internet 2.o), en el contexto del capitalismo en crisis y de las políticas de austeridad. La Generación B nace en torno al año 2000, llega a la juventud coincidiendo con el nacimiento de la web semántica (de internet 3.0), en el contexto de la reconstrucción del capitalismo poscrisis. En cuanto a los movimientos sociales característicos, la Generación @ va de la mano de los movimientos

\footnotetext{
7 En mi propia ciudad, Lleida, tuvo lugar una manifestación en apoyo a los inmigrantes sin papeles que habían acudido en plena pandemia para trabajar como temporeros de la fruta y que habían sido señalados por causar los brotes de coronavirus, en la que se pedía «Papers per tothom» (Papeles para todos).

8 Como se afirma en la convocatoria del presente monográfico, la acción colectiva de los nuevos y novísimos movimientos sociales «no se fundamenta en la unidad, ni en la identidad, ni en la totalidad sino en la potencia latente de la multiplicidad, de las singularidades, de la gran heterogeneidad posible en el estar juntos y estar en contra.»
} 
altermundialistas que señalan el acta de nacimiento de los novísimos movimientos sociales; la Generación \# coincide con los movimientos indignados y antiausteridad; y la Generación B se proyecta en las protestas airadas de 2019 que acabamos de resumir. En cuanto a sus actores protagonistas, la Generación @ se expresa a través del modelo de las biografías Peter Pan, es decir, de una juventud prolongada por la expansión de la sociedad de consumo; la Generación \# se expresa a través de las biografías replicantes, es decir, de una juventud hiperconectada y, al mismo tiempo, sin posibilidad de emanciparse; la Generación B se expresa a través de las biografías Cyborg, es decir, de una juventud que se encadena en bloques para enfrentar el riesgo de morir de éxito.?

Figura 3

Las tres generaciones digitales

\begin{tabular}{|c|c|c|c|}
\hline Dimensión & Generación @ & Generación \# & Generación B \\
\hline Periodo & $\begin{array}{l}\text { Nacimiento: } 1975-1985 \\
\text { Infancia: años ochenta } \\
\text { Adolescencia: años noventa } \\
\text { Juventud: primera década } \\
2000\end{array}$ & $\begin{array}{l}\text { Nacimiento: } 1985-1995 \\
\text { Infancia: años noventa } \\
\text { Adolescencia: primera década } \\
2000 \\
\text { Juventud: segunda década } \\
2000\end{array}$ & $\begin{array}{l}\text { Nacimiento: } 1995-2005 \\
\text { Infancia: primera década } \\
2000 \\
\text { Adolescencia: segunda } \\
\text { década } 2000 \\
\text { Juventud: } 2020 \text { y ss }\end{array}$ \\
\hline Contexto & $\begin{array}{l}\text { Web } 1.0 \\
\text { Capitalismo informacional } \\
\text { Nueva economía }\end{array}$ & $\begin{array}{l}\text { Web } 2.0 \\
\text { Capitalismo en crisis } \\
\text { Recesión }\end{array}$ & $\begin{array}{l}\text { Web } 3.0 \\
\text { Capitalismo poscrisis } \\
\text { Reconstrucción }\end{array}$ \\
\hline Significante & $\begin{array}{l}\text { @ arroba: } \\
\text { medida volumétrica } \\
\text { Mediterráneo, s. XV } \\
\text { Navegación }\end{array}$ & $\begin{array}{l}\text { \# hashtag: } \\
\text { medida numérica } \\
\text { América, s. XX } \\
\text { Conectividad }\end{array}$ & $\begin{array}{l}\text { B blockchain: medi- } \\
\text { da criptográfica } \\
\text { Internet, s. XXI } \\
\text { Interconexión }\end{array}$ \\
\hline Significado & $\begin{array}{l}\text { Digitalismo } \\
\text { Globalización } \\
\text { Unisexualismo } \\
\text { Pásalo }\end{array}$ & $\begin{array}{l}\text { Hiperdigitalismo } \\
\text { Relocalización } \\
\text { Bisexualismo } \\
\text { Trending topics }\end{array}$ & $\begin{array}{l}\text { Posdigitalismo } \\
\text { Deslocalización } \\
\text { Transexualismo } \\
\text { Fake News }\end{array}$ \\
\hline Rasgos & $\begin{array}{l}\text { Generación @ } \\
\text { Espacio global } \\
\text { Tiempo virtual } \\
\text { Nomadismo } \\
\text { Red }\end{array}$ & $\begin{array}{l}\text { Generación \# } \\
\text { Espacio glocal } \\
\text { Tiempo viral } \\
\text { Translocalismo } \\
\text { Rizoma }\end{array}$ & $\begin{array}{l}\text { Generación blockchain } \\
\text { No lugar } \\
\text { Slow time } \\
\text { The Wall } \\
\text { Holograma }\end{array}$ \\
\hline Ejemplos & $\begin{array}{l}\text { Subculturas } \\
\text { Altermundialismo } \\
\text { Comunidades virtuales } \\
\text { Teenagers } \\
\text { Biografías Peter Pan }\end{array}$ & $\begin{array}{l}\text { Escenas } \\
\text { Indignación } \\
\text { Microblogs } \\
\text { Tweenagers } \\
\text { Biografías replicantes }\end{array}$ & $\begin{array}{l}\text { Microculturas } \\
\text { Nueva extrema derecha } \\
\text { Sharing Society } \\
\text { Emerging Adulthood } \\
\text { Biografías cyborg }\end{array}$ \\
\hline
\end{tabular}

9 Esta tipología se corresponde con el análisis de Reguillo (2017) sobre la acción social colectiva/conectiva de la última década, en base a repertorios de protesta como el streaming, los memes y el hashtag. 


\section{Postscriptum: movimientos juveniles en la era viral}

La crisis del coronavirus parece haber paralizado, invisibilizado o silenciado los movimientos sociales que acabamos de reseñar, pero al mismo tiempo han convertido en prioritarias y urgentes las reivindicaciones que dichos movimientos expresan. La rápida expansión mundial de la pandemia nos ha hecho más conscientes de los efectos perversos de la globalización y del crecimiento sin límites, y al mismo tiempo de las enormes desigualdades que el tipo de globalización corporativa dominante comporta (Pleyers, 2020). La vulnerabilidad del ser humano y la necesidad de un consumo más sostenible nos enfrenta al reto de la emergencia climática. La importancia del trabajo de cuidados para enfrentar la pandemia (mayoritariamente asumidos por mujeres y por miembros de las minorías) nos recuerda la justicia de la reivindicación neofeminista y neocivilista. El hecho de que los jóvenes sean los menos afectados directamente por el virus, pero al mismo tiempo puedan ser vistos como los mayores transmisores, comporta la urgencia de plantear un nuevo contrato intergeneracional, que evite que los mayores mueran, pero también que los jóvenes sean las víctimas propiciatorias de la recesión que se avecina.

La Generación Blockchain corre el riesgo de convertirse en la Generación viral, en el doble sentido de exposición al coronavirus y de difusión viral de las informaciones, sean certeras o falsas (Feixa et al., 2020). Durante el periodo de confinamiento, en los países occidentales, los jóvenes contaron con dos mascarillas protectoras que los adultos no tenían o tenían menos: la cultura de la habitación y la cibercultura. En los países del sur global, donde el confinamiento fue difícil o imposible de poner en práctica, a menudo estas mascarillas podían brillar por su ausencia, pero se compensaron con la búsqueda de espacios comunitarios al aire libre o de usos alternativos y compartidos de internet. En el periodo de desconfinamiento los jóvenes sintieron la necesidad de recuperar el contacto con sus iguales, cuestionando la «distancia social» o compensándola con proximidad telemática.

El paisaje tras de la batalla contra el virus nos permitirá vislumbrar si la tecnología y la cultura blockchain han sido una vacuna o un factor añadido de exposición a la pandemia. En cualquier caso, los movimientos sociales que emerjan de la crisis del coronavirus deberán necesariamente encadenarse en bloques para defenderse de los embates de las grandes corporaciones transnacionales o estatales que querrán sacar partido de la lucha contra el virus, buscando chivos expiatorios en los sectores subalternos y amenazando con nuevas modalidades de juvenicidio físico o moral. 


\section{Referencias}

Aguilera, O. (2008). Movidas, movilizaciones y movimientos: cultura política y políticas de las culturas juveniles en el Chile de hoy [Tesis doctoral no publicada]. Universidad Autónoma de Barcelona.

Aytaç, E-, \& Stokes, S. (2020, 17 de febrero). Why Protest? Wilson Quarterly. http://bit.ly/3aokv5t Augé, M. (1996). Los no lugares: espacios del anonimato. Gedisa.

Burawoy, M. (1998). The extended case method. Sociological Theory, 16(1), 4-33. https:// doi.org/10.1111/0735-2751.00040

Cadena de bloques. (2019, 28 de febrero). En Wikipedia. http://bit.ly/3r8qWPS

Castells, M. (2012). Redes de indignación y esperanza. Alianza.

Diehl, J. (2019, 27 de octubre). From Hong-Kong to Chile, 2019 is the year of street protester, but why? The Washington Post. http://wapo.st/3nshXgY

Feixa, C. (2000). Generación @: la juventud en la era digital, Nómadas, (13), 76-91.

Feixa, C. (2006). Generación XX: teorías sobre la juventud en la era contemporánea. Revista Latinoamericana de Ciencias Sociales, Niñez y Juventud, 4(2), 21-45.

Feixa, C. (2016). De la Generación@ a la \#Generación: la juventud en la era digital. NED.

Feixa, C. (2020). Els joves i l'emergència climàtica. Serra d'Or, (724), 28-33.

Feixa, C., \& Andrade, C. (2020). El rey: diario de un Latin King. NED.

Feixa, C., Fernández-Planells, A., \& Figueras, M. (2016). Generación hashtag: los movimientos juveniles en la era de la web social, Revista Latinoamericana de Ciencias Sociales, Niñez y Juventud, 14(1), 107-120.

Feixa, C., Leccardi, C., \& Nilan, P. (Eds.) (2016). Youth, space \& time: Agoras and chronotopes in the global city. Brill. https://doi.org/10.1163/9789004324589

Feixa, C., Méndez, A., \& Feixa, C. (2020). Adolescentes confinad@s. NED.

Feixa, C., \& Nofre, J. (Eds.) (2013). \#GeneraciónIndignada: topías y utopías del 15M. Milenio.

Feixa, C., Pereira, I., \& Juris, J. J. (2009). Global citizenship and the 'new, new' social movements: Iberian connections. Young, 17(4), 421-442. https://doi.org/frznnr

Feixa, C., Sánchez-García, J., Ballesté, E., Cano, A. B., Masanet, M. J., Mecca, M., Oliver, M. (2019). The (Trans) gang: Notes and queries on youth street group research. Universitat Pompeu Fabra; European Research Council. https://oi.org/10.31009/ transgang.2019.wpo2.1 
Fernández-Planells, A. (2015). Análisis del uso de los medios por las generaciones más jóvenes: el movimiento $15 \mathrm{M}$ y el Umbrella Movement. El Profesional de la Información, 24(4), 371-379. https://doi.org/10.3145/epi.2015.jul.03

Juris, J. S. (2008). Networking futures: Movements against corporate globalization. Duke University Press.

Movimientos sociales de 2019. (2020, 20 de junio). En Wikipedia. https://bit.ly/3gYmiza

Muñoz, G. (2010). Las redes sociales: ¿fórmula mediática contra la soledad y el aburrimiento? Revista Latinoamericana de Ciencias Sociales, Niñez y Juventud, 8(1), 51-64.

Palacios, N. (2017). Revolución de la Web 3.o [Video]. TED Conferences. https://bit.ly/3mwhDpv Pleyers, G. (2020, 16 de julio). De la pandémie à un autre monde? The Conversation. http:// bit.ly/3mEU2mJ

Protestas por la muerte de George Floyd. (2020, 11 de agosto). En Wikipedia. http://bit.ly/3akNI17

Pires, L., \& Feixa, C. (en prensa). Movimentos sociais juvenis enquanto contra espaços: dos novíssimos movimentos sociais ao 8M $2019 \mathrm{em}$ Barcelona. En Jovens em movimento. Universidade Estadual do Centro Oeste do Paraná.

Reguillo, R. (2017). Paisajes insurrectos: jóvenes, redes y revueltas en el otoño civilizatorio. NED. Sánchez-García, J., Ballesté, E., \& Feixa, C. (2019). ¿Qué fue de la primavera indignada? Milenio.

Sánchez-García, J., \& Touhtou, R. (2021). De la Hogra al Hirak: neocolonialismo, memoria y disidencia política juvenil en el Rif. Revista Latinoamericana de Ciencias Sociales, Niñez y Juventud, 19(1), 1-20. https://dx.doi.org/10.116oo/rlcsnj.19.1.4591

Soler, R., Ballesté, E., \& Feixa, C. (en prensa). Desde la periferia: la noción de espacio social en la movilización sociopolítica de la juventud.

Tapscott, D. (1998). Growing up digital: The rise of the net generation. McGraw-Hill.

Tapscott, D., \& Tapscott, A. (2016). La revolución blockchain. Deusto.

Web 1.o. (2019, 17 de enero). En Wikipedia. http://bit.ly/3paXSW1

Web 2.o. (2019, 27 de febrero). En Wikipedia. http://bit.ly/3p4FEFU

Web 3.o. (2019, 20 de febrero). En Wikipedia. http://bit.ly/3h1K3q1 